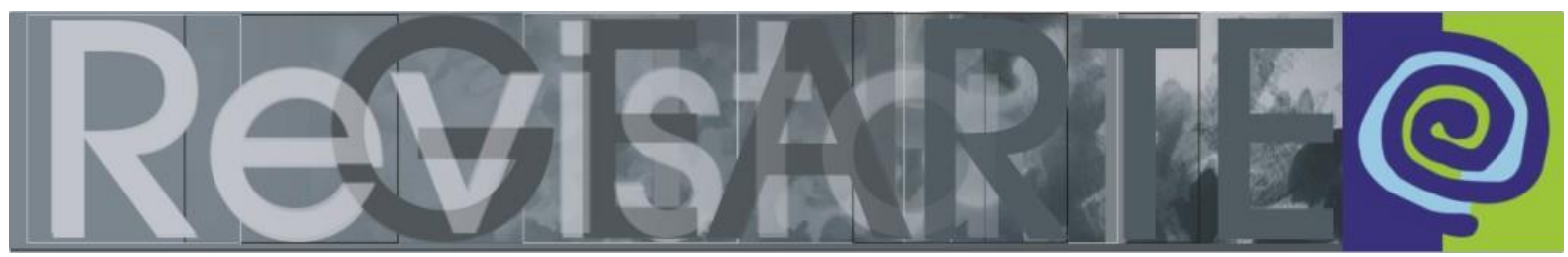

e-ISSN 2357-9854

\title{
Abordagem Triangular e performance: reflexões e possibilidades pedagógicas na sala de aula
}

\author{
Amanda Caline da Silva Omar (Universidade Federal \\ da Paraíba - UFPB, João Pessoa/ PB, Brasil) \\ Diogo José de Moraes Lopes Barbosa (Universidade Federal \\ da Paraíba - UFPB, João Pessoa/ PB, Brasil) \\ Guilherme Barbosa Schulze (Universidade Federal \\ da Paraíba - UFPB, João Pessoa/ PB, Brasil)
}

\begin{abstract}
RESUMO - Abordagem Triangular e performance: reflexões e possibilidades pedagógicas na sala de aula - Temos notado um aumento das pesquisas relacionadas ao ensino de arte no Brasil com foco na Abordagem Triangular. Estas pesquisas têm ajudado na democratização do ensino de arte, assim como nos processos de transdisciplinaridade entre as diferentes linguagens artísticas e as demais disciplinas. Neste ponto, começamos a refletir sobre o lugar da performance enquanto linguagem independente das demais. Analisamos, ao longo do artigo, a possibilidade da sua presença em sala de aula, além de sua utilização na disciplina de arte, com conteúdos específicos, reflexões, e práticas de produções individuais e coletivas. Nossas reflexões se concentraram nas das ideias de alguns teóricos que discorrem sobre arte/educação, além de outros que pensam linguagem da performance. A intenção será criar relações entre o ensino de artes, a performance e a Abordagem Triangular.
\end{abstract}

\section{PALAVRAS-CHAVE}

Performance e Educação. Pedagogia da Performance. Abordagem Triangular.

ABSTRACT - Triangular approach and performance: reflections and pedagogical possibilities in the classroom - We have noticed an increase in research related to art teaching in Brazil focusing on the Triangular Approach. These researches have helped in the democratization of the teaching of art, as well as in the processes of transdisciplinarity between different artistic languages and other disciplines. At this point, we started to reflect on the place of performance as a language independent of the others. We analyzed in this article the possibility of its presence in the classroom, besides its use in the art discipline, with specific contents, reflections, and practices of individual and collective productions. Our reflections focused on the ideas of some theorists who talk about art / education, as well as others who think performance language. The intention will be to create relationships between arts education, performance and the Triangular Approach.

KEYWORDS

Performance and Education. Pedagogy of Performance. Triangular Approach.

\section{Introdução}

Os primeiros caminhos para a redação deste artigo surgiram a partir das vivências e experiências de nosso cotidiano em sala de aula. Como educadores da 
rede pública de ensino, percebemos, ao longo de nossas práticas, a necessidade de trazer para as aulas do Componente Curricular Arte, a performance enquanto linguagem artística com conteúdos específicos.

Desta forma, nossa busca se concentrou na tentativa de compreender melhor o lugar da performance no universo epistemológico da arte/educação no Brasil, permitindo assim, refletir sobre os processos de ensino/aprendizagem e de criação de saberes ligados a ela.

As reflexões contidas aqui desenvolveram-se paralelamente aos caminhos percorridos durante a disciplina de Performance e Performatividade na Cena Contemporânea, cursada no Mestrado em Artes da Universidade Federal da Paraíba (UFPB) no ano de 2016. Os estudos e experiências vividos no decorrer da disciplina possibilitaram a ampliação do olhar a respeito dos conceitos de performance e, principalmente, dos processos artísticos e pedagógicos que envolvem a prática performativa em sala de aula. Estes processos podem ser desenvolvidos com intenção de contribuir na construção de pensamentos que colaborem para enlaçar os campos teóricos e práticos deste universo, além de estimular o uso dessa linguagem artística no cotidiano do ensino de artes na escola formal.

Lembremos que desde a década de 1990 as políticas públicas contemplam a performance, como se vê nos $\mathrm{PCNs}^{1}$ do componente Arte:

As artes visuais, além das formas tradicionais (pintura, escultura, desenho, gravura, arquitetura, artefato, desenho industrial), incluem outras modalidades que resultam dos avanços tecnológicos e transformações estéticas a partir da modernidade (fotografia, artes gráficas, cinema, televisão, vídeo, computação, performance) (BRASIL, 1997, p. 45, grifo nosso).

Desta forma, vemos que os PCNs de Arte se mostram bastante claros quando sugerem a existência da performance como conteúdo (ou linguagem artística) a ser visto na parte de artes visuais. Sabemos, contudo, que poucos professores

1 O componente curricular Arte está sendo discutido na elaboração da BNCC (Base Nacional Comum Curricular), cuja versão final ainda não foi divulgada. Conforme a versão preliminar, a Arte é constituída pelas linguagens: Artes Visuais, Dança, Música e Teatro, sendo que a performance é mencionada como forma de expressão artística. Cf: http://basenacionalcomum.mec.gov.br/images/BNCC_publicacao.pdf. 
apresentam esta linguagem para os estudantes, talvez pelo fato de se tratar de uma expressão nova na história das artes praticadas pelo homem e, sobretudo, pela complexidade poética, estética, conceitual e política que a linguagem da performance possui.

Ainda que o professor de arte vá ao encontro a tais conteúdos, outras questões surgem: que abordagens metodológicas podem ser interessantes na apresentação desta linguagem ao aluno, de modo que ele possa usufruir e se apropriar deste conhecimento de forma significativa? Boa parte das teorias pós-modernas da arte/educação no Brasil, quando enveredam pelo caminho de investigar proposições metodológicas no ensino das artes, convergem para Abordagem Triangular, proposta sistematizada pela professora e pesquisadora Ana Mae Barbosa no final dos anos de 1980. Desta maneira, nosso percurso não foi diferente, seguimos os caminhos de tais pensamentos, com intenção de sanar as dúvidas diante de nossas práticas de ensino da performance no ambiente escolar.

Assim, nossa investigação se concentrou em responder à pergunta: quais aspectos se encontram na relação entre a Abordagem Triangular e a performance como linguagem artística na sala de aula?

\section{(Des)estruturação do conceito de performance}

O termo performance possui vários significados, dependendo do contexto no qual seja aplicado. Segundo Schechner (2003), seu sentido estaria ligado ao desempenho de alguém: ter uma boa performance significaria que o sujeito realizou algo com alto padrão, que superou as expectativas, foi bem-sucedido. Sob os aspectos artísticos, encontramos no Dicionário de Teatro (PAVIS, 2008), a definição do termo ligando-o a práticas de outras artes, de forma interdisciplinar, com a dança, teatro, música, vídeo, poesia e cinema, e que poderia ser apresentada em espaços diferentes como na sala de cinema, nos edifícios teatrais, nas galerias de arte ou nos museus, e que seria caracterizada principalmente por sua efemeridade.

Historicamente, no campo dos estudos da arte, quando ouvimos a palavra performance, nos remetemos às artes corporais, criando como referências às 
produções das décadas de 1960 e 1970. Isto nos leva a pensar nas práticas artísticas que eram formuladas baseadas no próprio artista, no seu corpo, sendo ao vivo e que deveriam ser vistas por um público em um tempo e espaço específicos (MELIM, 2008). Isso se deve ao fato de que este fenômeno artístico teve uma relação muito próxima e ambígua à arte conceitual, que utilizava na época, principalmente o corpo do artista como objeto de suporte para obra e também, a vida como aparato para a construção.

Para Shechner (2003, p. 28), existem quatro palavras chave para definir performance: vida cotidiana, restauração de comportamento, teatro e rituais. $O$ autor explica que as "Performances são feitas de pedaços de comportamento restaurado, mas cada performance é diferente das demais [...] a performance não está em nada, mas entre si.", ou seja, vai além do nosso desejo de mostrar uma performance, de elaborar um plano de trabalho, está entre essa mistura de vida cotidiana e a restauração desse comportamento, está além de nós, pois, nos envolve e envolve o outro.

Os estudos críticos mais recentes têm repensado a noção de performance nas artes a partir das possibilidades de alargamento das referências que o termo contém, elaborando novos conceitos que não limitam a ideia apenas ao hibridismo, como arte que mistura todas as outras. Na perspectiva dessa ampliação, Melim (2008) cita Kristine Stiles ao afirmar que as performance acontecem em gestos simples, sejam apresentadas por um único artista, um coletivo, experiências individuais ou não, podendo envolver grandes ou pequenos espaços, estando ao vivo ou sem audiência alguma.

Roselee Goldberg (2006) aponta outra referência sobre performance, apresenta-a como uma linguagem independente em seu fazer artístico, que mostra conceitos das produções artísticas dos anos de 1970, dando vida a ideias baseadas em criações artísticas de movimentos vanguardistas e afirmando que o uso da presença do artista seria o diferencial na sua produção.

As possibilidades de alargamentos desses referenciais não estão apenas ligadas ao corpo, aos novos hibridismos artísticos ou à presença, mas também, para Melim (2008), é necessário também tentar 
[...] substituir o estereótipo que associa a noção de performance a um único formato -tendo o corpo como núcleo de expressão e investigação, análogo à body art-por um viés bem mais distendido. E, ainda por incluir na construção de sua trajetória, não somente ações ao vivo compartilhadas por um público, que recusam deixar evidências ou qualquer tipo de existência do trabalho, ou ações dessa natureza que deixam rastros a partir de uma série de remanescentes, mas outras formas de desdobramentos desses procedimentos, através de um número diverso de situações apresentadas em muitos discursos críticos, curatoriais, acadêmicos e artísticos (MELIM, 2008, p. 108).

A busca de novos horizontes propostos pela autora, expandiria o conceito da performance, mostrando-a como uma linguagem artística aberta à múltiplas concepções, sem que haja limites ou, principalmente, exista um consenso sobre o debate. Assim, tais questionamentos de cunho poético e estético estariam abertos e em constante mudança, pois, pensar sobre performance seria equivalente a imaginar infinitos desdobramentos, sem imitações que cerceiam o objeto em questão, além de propiciar variadas possibilidades de criação.

\section{Entrecruzamentos da pedagogia e performance}

Existe há algum tempo, pesquisas que promovem a reflexão sobre o termo performance, sua estética, elaboração, construção, receptividade, limites que envolvem artistas e espectadores, todos esses aspectos têm sido encontrados com facilidade nas análises sobre o tema. Seu conceito, quando considerado a partir dos seus significados, poderia ser genérico, visto que sua utilização é encontrada em distintas áreas do conhecimento e também é empregada em discursos diversos. Além disso, podemos ainda afirmar que são recentes os movimentos que se debruçam a analisar a performance como linguagem não apenas artística, mas também pedagógica.

Neste sentido, o termo Pedagogia da Performance, mesmo que ainda timidamente, está presente em alguns espaços de produção de conhecimento como universidades, centros de pesquisa, grupos artísticos de cunho experimental etc. Segundo Fred Nascimento (2014):

A Pedagogia da Performance investe na inclusão da subjetividade na prática pedagógica, na exploração da autonomia, promovendo uma busca de realização pessoal partindo do próprio interesse de cada indivíduo. Proporciona a criação de vínculos entre os participantes da ação, libera a 
afetividade. O sujeito é também avaliador do processo, o que inclui autoavaliação e autocrítica (NASCIMENTO, 2014, p. 62).

Partilhando de tais conceitos, no contexto contemporâneo, se faz necessário pensar nas linguagens artísticas como objetos híbridos e interdisciplinares, que estão em constante diálogo entre si e com outros elementos ao seu redor. Se a performance interage com os ambientes externos ao museu, se ela acontece nos espaços públicos, se não é o espectador que vai de encontro a ela, mas sim, o inverso disso, por que não levarmos a performance ao encontro do aluno? Esta possibilidade faz com que criemos no espaço escolar novas oportunidades de expressão para os envolvidos.

A reconfiguração da educação na atualidade exige que novos fazeres artísticos pedagógicos venham à tona, experimentando elementos artísticos de formas diferentes, de modo a proporcionar aos estudantes algo diverso, que gere interesse, debate e reflexão sobre a produção artística, além de estimular com que o fazer artístico esteja presente também nestas vivências. Assim, a pedagogia da performance tem ganhado espaço nas discussões cotidianas dos arte/educadores, contudo, ainda são poucos os trabalhos relacionados a essas práticas. Podemos afirmar que experiências utilizando essa linguagem na disciplina de arte nas escolas públicas brasileiras ainda não são largamente compartilhadas.

Os estudos que envolvem as pesquisas em performance e a educação levam em consideração o papel do sujeito nesse contexto, com suas vozes, identidades, raça, gênero, e tudo que envolve a construção e produção do conhecimento nesta linguagem artística, isto por parte de educadores e educandos. O lugar de estar "entre", que a performance ocupa, também permite compreende-lo como um lugar que congrega ideias e conhecimento:

\footnotetext{
Essa noção de reunião, de encontro, de interação da performance poderia ser tomada como modelo para Educação. Educação não deve significar simplesmente sentar-se e ler um livro ou mesmo escutar um professor, escrever no caderno o que dita o professor. A educação precisa ser ativa, envolver num todo mentecorpoemoção - tomá-los como uma unidade (SCHECHNER; ICLE; PEREIRA, 2010, p. 26).
}

Essa citação reforça a ideia de que a educação tradicional inclui o aluno em um processo passivo de ensino/aprendizagem, dessa forma, a performance vai de 
encontro a uma compreensão do mundo unificado e também aberto em suas ideias e ações, tornando o processo educacional ativo e crítico, convergindo os espaços da mente, os processos corporais e as emoções.

Dentro da escola, o espaço que a performance pode ganhar na educação assume, em primeiro plano, uma forma metafórica para os professores, permitindo assim, incentivar maneiras de ensinar que sejam mais participativas e envolvam os alunos de forma mais efetiva. Pineau (2010) descreve que os professores podem ser incentivados a terem uma postura quase de artistas em sala de aula, regentes orquestrando as experiências de aprendizagem diárias, como contadores de histórias ou mesmo, atores teatrais. Neste tópico, podemos ainda adentrar ao conceito de professor-performer. Fred Nascimento (2014) nos mostra que

\begin{abstract}
Esse professor-performer é um intermediador que provoca a troca de material simbólico entre os indivíduos envolvidos no processo. A criatividade flui entre as formas, os intercâmbios. O professor-performer também é um praticante da ação. O professor-performer investe sua energia e conhecimento para que essas expressões cheguem a todos, procura-se a adaptação do professorperformer ao grupo e a cada sujeito, incentivando a busca individual e coletiva, a troca de informações e o diálogo. Nas oficinas laboratoriais quebra-se com o racionalismo extremo e com vários tipos de bloqueios, como o medo, o ridículo, bloqueios culturais e visão estreita (NASCIMENTO, 2014, p. 62).
\end{abstract}

A partir destes pensamentos, poderíamos entender que a sala de aula teria a possibilidade de se tornar um espaço com potencial estético para criação artística, com todo tipo de público, seja ele passivo ou ativo nas relações de criação. Sob essa perspectiva, Pineau elabora o conceito de pensar a educação como elemento performativo. Seria, então, performance no âmbito da escola, todas as relações criativas construídas a partir de uma prática artístico/pedagógica.

Como já afirmamos, os estudos no Brasil com relação à performance e educação ainda são raros, porém possíveis, por permitir as práticas de criação de conhecimentos, de experiências, de análise estética, de debates e, principalmente, de produção artística performática dentro das instituições educacionais. Contudo, faz-se necessário ainda pensar de que maneira essa linguagem artística colabora para a construção de uma prática educativa contemporânea que permita aos alunos, pensar, analisar e criar dentro do contexto do ensino de artes na realidade brasileira? 
Se entendermos performance como uma arte da presença, isto nos faz pensar que $o$ ato pedagógico é um processo que exige o estado presente dos envolvidos. É uma ação multidimensional que tem inúmeras funções na transmissão, elaboração e solidificação de conhecimentos. Um ato de encontros e que está também "entre" os encontros e "entre" os saberes construídos. A performance traria para o espaço escolar possibilidades mutáveis e contínuas, erradicando o currículo linear de acumulação, permitindo entrecruzar as competências disciplinares, sejam elas específicas ou isoladas.

\section{Performance e Abordagem triangular}

Analisando mais uma vez os PCNs de Arte (BRASIL, 1997), observando as quatro linguagens artísticas apresentadas (Arte, Dança, Teatro e Música), percebemos claramente o predomínio de uma avaliação baseada na Abordagem Triangular, que propõe o fazer, o saber pensar sobre aquilo que é produzido e a contextualização daquilo que é trabalhado, são os vértices do triângulo proposto por Ana Mae Barbosa. Nesse processo, podemos entender "[...] por premissa básica a integração do fazer artístico, a apreciação da obra de arte e sua contextualização histórica [...]" (PENNA, 2001, p. 39) como elementos fundamentais para o ensino/aprendizagem nas linguagens artísticas apresentadas.

Machado (2012) afirma que podemos ter como ponto de partida para compreensão da Abordagem Triangular alguns critérios de avaliação elencados pelos seguintes verbos: nas Artes Visuais há o criar; conhecer; valorizar a pesquisa. Em Teatro, o improvisar; emitir opiniões; valorizar as fontes de documentação. Já na Música tem-se o interpretar; utilizar conhecimentos; reconhecer e comparar composições, e por fim, na Dança, saber mover-se com consciência; expressar com clareza suas ideias a respeito das danças que cria e assiste; conhecer correntes históricas da dança.

Se destacarmos em cada linguagem alguns pontos como a movimentação, a criação, a improvisação e interpretação, podemos pensar as práticas da arte contemporânea, e principalmente as da performance, como ações oriundas de processos de miscigenações e de acontecimentos concomitantes, permitindo a união 
e o entrelaçamento das experiências artísticas de cada sujeito em meio a esses processos.

Porém, a performance não exige linearidade em seu processo de construção poética, possibilitando com que os vértices da Abordagem Triangular, possam ser executados sem uma ordem definida e assim, aconteçam ao mesmo tempo, deformando o triângulo em uma espiral, permitindo com que todos os aspectos sejam perpassados no percurso de aprendizagem, mas que não voltem ao ponto inicial pelo mesmo caminho nem da mesma maneira. Além disso, se faz necessário que estes elementos se transformem em cada passagem por todos os pontos do triângulo.

Por ter uma natureza subjetiva, em relação aos processos de produção artística, as artes trariam para experiência pedagógica vivências diversificadas, visto que as experiências artísticas estão presentes nas "[...] relações de fazer e padecer, e a energia de ida e vinda que faz com que uma experiência seja uma experiência [...]", constituindo um diálogo entre o teórico e o empírico (BARBOSA, 1998, p. 23).

Cunha (2010) afirma que a Abordagem Triangular estaria em diálogo com o tempo, dessa maneira seria uma abordagem em processo, contínua e inacabada, tornando-a de natureza conceitual e dialogal, que se flexibiliza com a contemporaneidade. Essas características se fazem presentes na performance e colaboram para compreender o processo de edificação da proposta de encontro entre a Abordagem Triangular e a performance.

É por esse motivo que a Abordagem Triangular, em sua natureza inicial, dialoga com vários aspectos da performance. Ela não é uma teoria que se fecha dentro de si, mas que interage com os elementos ao seu redor, que não lida com o conhecimento de forma cartesiana e disciplinarizada, mas que permita a movimentação de ideias e a interação de suas partes. O contrário de tais conceitos dificilmente traria aspectos benéficos, tanto para a arte da performance como para a arte/educação de uma forma geral, pois, como afirma Rizzi (2008), também em relação à Abordagem Triangular, "A maneira disciplinarizada de conceber o ensino é fragmentada, resulta em prejuízo qualitativo e quantitativo. Impede a visão do todo e não favorece a intercomunicação entre as várias áreas do conhecimento" (RIZZI, 2008, p. 344). 
Essa possível abordagem dos caminhos pedagógicos da performance modificaria as formas de fazer, criar, refletir a linguagem em questão, permitindo assim, criar novos sentidos, novas poéticas e renovar a construção de pensamentos que envolvem a prática performática, sobretudo, envolvendo outro ambiente de suma importância na proliferação e manutenção destes processos artísticos: a escola.

\section{Considerações finais}

O ensino de arte pós-moderno avançou em diversos aspectos acerca das pesquisas e teorias que envolvem os processos pedagógicos e educacionais do ensino de artes. Na história da arte/educação, passamos por diversos momentos diferentes, em alguns períodos se privilegiava um ensino baseado apenas no fazer livre de teorias ou influências e em outros, a criação a partir de uma lógica tecnicista, presente apenas para beneficiar a produção industrial e o universo do trabalho. Hoje a arte é vista como conhecimento, como área de estudo específica onde $\mathrm{o}$ ato de apropriação de seus conceitos é fundamental para que se tenha uma aprendizagem significativa.

A Abordagem Triangular faz parte disso, pois ela não está presente apenas para sanar os anseios e as dúvidas dos professores de arte, tão pouco para impor limitações ao ensino. Como a própria Ana Mae Barbosa nos fala, não estamos fazendo uso de uma metodologia, pois, quanto a isto, cada professor tem a sua. Estamos nos referindo a uma abordagem de ensino, a uma forma de como enxergamos e praticamos a ação de educar, que envolve outras questões: éticas, estética, filosóficas, políticas.

O ensino da performance passa por estes três aspectos (o curricular, o artístico e o metodológico). Estes três aspectos devem caminhar juntos e a Abordagem Triangular pode ser um elemento de coesão. Para isso, é necessário que o próprio arte/educador se aprofunde nestas teorias, tanto dos aspectos pedagógicos como artísticos, mantenha sempre um espírito investigativo e questionador.

As repostas não surgem de receitas, as inquietações estão sempre presentes e é fundamental que elas estejam, assim como a própria arte da performance em seu 
surgimento. Nós, enquanto professores, não devemos nos contentar com o que temos ou com o que nos dizem que devemos fazer. Devemos procurar, questionar, investigar, e quando necessário, modificar a realidade. Tanto a educação, a arte, e a própria performance, tem como objetivos a transformação, seja das pessoas (espectadores, professores, alunos), dos materiais e processos ou mesmo, da própria realidade que nos cerca.

\section{Referências}

BRASIL. Ministério da Educação, Secretaria de Educação Fundamental. Parâmetros curriculares nacionais: Arte. Brasília: MEC/SEF, 1997.

BARBOSA, Ana Mae. Tópicos utópicos. Belo Horizonte: C/Arte, 1998.

CUNHA, Fernanda Pereira da. E-arte/educação crítica. In: BARBOSA, Ana Mae; CUNHA, Fernanda Pereira da. Abordagem triangular no ensino de artes e culturas visuais. (Orgs.). São Paulo: Cortez, 2010. p. 249-284.

GOLDBERG, Roselee. A arte da performance: do futurismo ao presente. São Paulo: Martins Fontes, 2006.

MACHADO, Mariana Marcondes. Fazer surgir antiestruturas: abordagem em espiral para pensar o currículo em arte. Revista e-curriculum, São Paulo, v. 8, n. 1, p. 1-21, 2012.

MELIM, Regina. Performance nas artes visuais. Rio de Janeiro: Jorge Zahar, 2008.

NASCIMENTO, Fred. Grupo Totem: formação do ator-performer como ação cultural. In: SILVA, Igor de Almeida; CONSTÂNCIO; Rudimar (Orgs.). Ação cultural: arte, educação e cultura. Recife: SESC Pernambuco, 2014. p. 58-67.

PENNA, Maura. É este o ensino de arte que queremos? João Pessoa: UFPB, 2001.

PINEAU, Elyse Lamm. Nos cruzamentos entre performance e a pedagogia: uma revisão prospectiva. Revista Educação \& Realidade, Porto Alegre, v. 35, n. 2, p. 89-114, 2010.

SCHECHNER, Richard. O que é performance? O Percevejo: Revista de Teatro Crítica e estética, Rio de Janeiro, Ano 11, n. 12, p. 25-50, 2003.

SCHECHNER, Richard; ICLE, Gilberto; PEREIRA, Marcelo. O que pode a performance na educação? Uma entrevista com Richard Schechner. Revista Educação \& Realidade, Porto Alegre, v. 35, n. 2, p. 23-35, 2010.

PAVIS, Patrice. Dicionário de Teatro. São Paulo: Perspectiva, 2008.

RIZZI, Maria Christina de Souza Lima. Reflexões sobre a Abordagem Triangular do Ensino da Arte. In: BARBOSA, Ana Mae (Org.). Ensino da arte: memória e história. São Paulo: Perspectiva, 2008. p. 335-348.

\section{Amanda Caline da Silva Omar}

Licenciada em Educação Artística com Habilitação em Artes Cênicas - Universidade Federal de Pernambuco; Especialista em Educação Especial pela Faculdade Frassineti do Recife; Aluna no Mestrado Profissional em Artes da Universidade Federal da Paraíba; professora na rede municipal de ensino de João Pessoa.

E-mail: amandacaline@hotmail.com

Currículo: http://lattes.cnpq.br/3613736455582943 


\section{Diogo José de Moraes Lopes Barbosa}

Licenciado em Educação Artística com Habilitação em Artes Cênicas - Universidade Federal de Pernambuco; Especialista em Estudos Cinematográficos - Universidade Católica de Pernambuco. Aluno do Programa de Mestrado em Artes da Universidade Federal da Paraíba. Professor de Artes e Cinema na educação formal e não formal.

E-mail:diogo_barbosa@hotmail.com

Currículo: http://lattes.cnpq.br/6845530989853825

\section{Guilherme Barbosa Schulze}

Professor do Departamento de Artes Cênicas da Universidade Federal da Paraíba, no Mestrado Profissional em Artes (PROFARTES) e Mestrado Acadêmico em Artes Visuais (UFPB-UFPE), dos cursos de graduação em teatro e dança. Graduado em Música - Universidade Federal da Paraíba; Especialista em Coreografia - Universidade Federal da Bahia, Mestre em Artes - Universidade Estadual de Campinas e PhD em Estudos da Dança - Universidade de Surrey, Inglaterra.

E-mail: guilherme.schulze@gmail.com

Currículo: http://lattes.cnpq.br/2239717664426193

Recebido em 28 de fevereiro de 2017 Aceito em 23 de julho de 2017 